\title{
Smoking behaviour, knowledge and perceived susceptibility to lung cancer among secondary- school students in Amman, Jordan
}

H.M. Shadid ${ }^{7}$ and S.Z. Hossain ${ }^{7}$

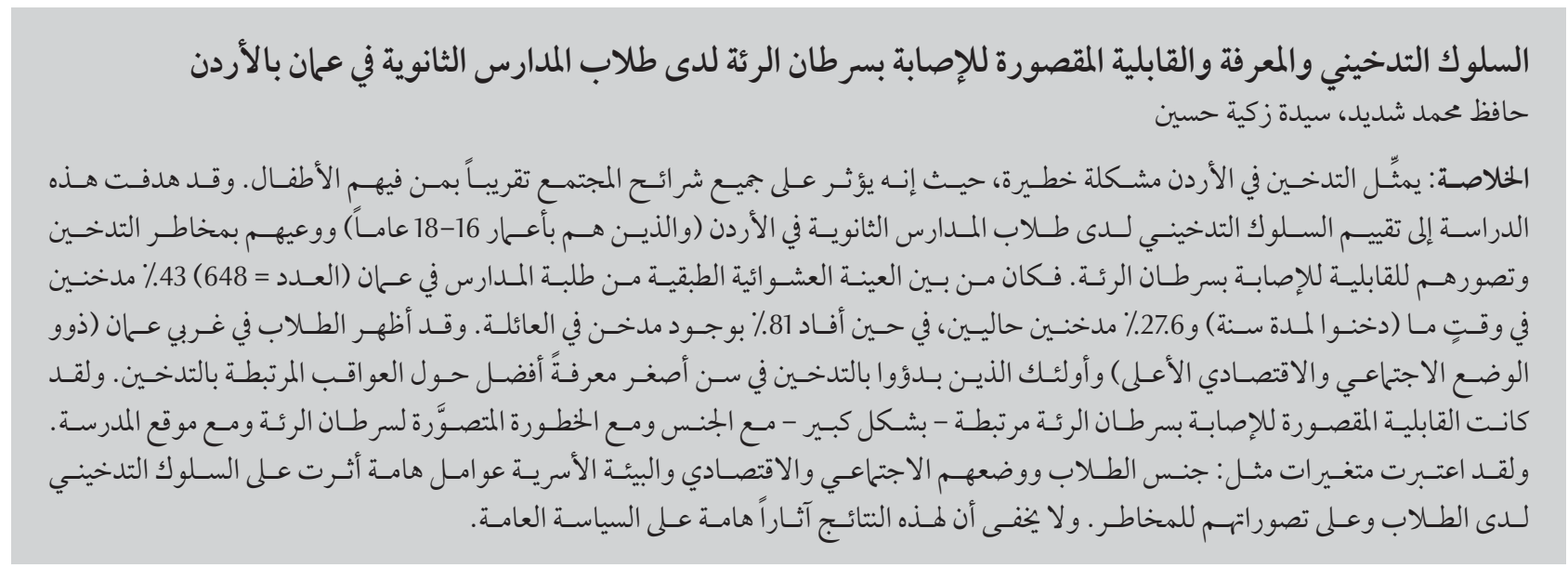

ABSTRACT Smoking in Jordan is a serious problem as it affects almost all segments of society including children. This study aimed to evaluate the smoking behaviour of Jordanian secondary-school students (aged 16-18 years), their awareness of the dangers of smoking and their perceived susceptibility to lung cancer. Of the stratified random sample of students from Amman schools ( $n=648$ ), 43\% were ever smokers (had smoked for 1 year) and $27.6 \%$ were current smokers, while $81 \%$ reported having a smoker in the family. Students in western Amman (higher socioeconomic status) and those who started smoking at a younger age demonstrated better knowledge about smoking-related consequences. Perceived susceptibility to lung cancer was significantly associated with sex, perceived seriousness of lung cancer and school location. Students' sex, socioeconomic status and the family environment were important factors that influenced students' smoking behaviour and risk perceptions and these findings have significant policy implications.

Comportement et connaissances en matière de tabagisme de lycéens à Amman (Jordanie) et probabilité perçue de cancer du poumon

RÉSUMÉ Le tabagisme en Jordanie est un problème grave car il touche presque toutes les couches de la société et notamment les enfants. La présente étude réalisée visait à évaluer le comportement en matière d'usage du tabac fumé de lycéens (âgés de 16 à 18 ans) en Jordanie, leur sensibilisation aux dangers du tabagisme et la probabilité d'être atteints d'un cancer du poumon selon eux. Au sein de l'échantillon randomisé stratifié de lycéens scolarisés à Amman ( $n=648), 43 \%$ avaient déjà consommé du tabac fumé (pendant un an) et 27,6 \% étaient des fumeurs actifs, tandis que 81 \% ont déclaré avoir un fumeur dans leur famille. Des lycéens de l'ouest d'Amman (au statut socioéconomique plus élevé) et ceux qui avaient commencé à fumer à un âge plus jeune avaient de meilleures connaissances sur les conséquences liées au tabagisme. La probabilité perçue d'un cancer du poumon était fortement associée au sexe, à la compréhension de la gravité d'un tel cancer et à la situation géographique de l'école fréquentée. Le sexe, le statut socioéconomique et l'environnement familial étaient des facteurs importants qui influaient sur le comportement des lycéens en matière de tabagisme et sur leurs perceptions du risque. Ces résultats ont des implications politiques importantes. 


\section{Introduction}

The adverse health effects of tobacco smoking have been widely recognized as a global concern. The World Health Organization (WHO) has attributed around 5 million deaths per year to tobacco smoking, a figure expected to rise to more than 8 million by 2030 given current trends in tobacco use (1). At the same time, the morbidity and mortality associated with tobacco use is shifting from developed to developing countries, in which estimates suggest almost $70 \%$ of deaths will take place (2). One of those countries is Jordan, which has a population of more than 6 million and is classified by the World Bank as an upper-middle-income country with severely scarce resources (3).

Smoking in Jordan is a serious problem that needs to be targeted urgently as it affects almost all segments of society including children. In spite of the existing laws and control efforts in place, including a total ban on smoking in public transport and government offices, and newly introduced legislation to control smoking in restaurants, surveys show that $40-50 \%$ of adult men currently smoke (4). While the prevalence of smoking among females is reported to range from only 5 to $15 \%(4,5)$, these rates could be under-reported as it is not usually considered socially acceptable for women to smoke (5). Smoking by women is an important area for further exploration given the male-dominated nature of the society.

The Global Youth Tobacco Survey (GYTS) performed on 13-15 year-old Jordanian students in 2007 showed a fairly high prevalence of current smoking of $10.3 \%$ (13.2\% in males and $7.1 \%$ in females) (6). A recent study on a younger cohort (7th-grade students) in Irbid, Jordan reported a prevalence of current smoking (cigarettes or waterpipe) of $22.9 \%$ in boys and $8.7 \%$ in girls (7). This is a high prevalence in a country where more than half of the population is under the age of 18 years (8). Studies have shown more than three-quarters of students in Jordan reported people smoking in their presence on at least one occasion in the previous 7 days (6). Another study reported that $65.7 \%$ of male smokers in Jordan started their habit at school age, before reaching 18 years old (9).

There appears to be very little research into smoking behaviour among young people aged $16-18$ years in Jordan, and this study is an attempt to fill the gap. The aim of this study was to examine the correlates of smoking behaviour among secondary-school students attending public or private schools in the eastern and western suburbs of Amman. The health belief model proposes that individuals' perceptions of their susceptibility combined with their perception of the severity of a disease results in their assessment of the perceived threat of disease and this determines their motivation to change their behaviour (10). The study therefore also identified the predictors of students' knowledge and their perceptions of the severity of lung cancer and their susceptibility to it as a consequence of smoking.

\section{Methods}

\section{Participants and recruitment}

This paper is based on a quantitative study of secondary-school students aged 16-18 years in Amman, Jordan. Stratified random sampling was used to select schools and to recruit eligible participants $(n=648)$. A total of 24 schools were selected randomly out of all 155 secondary schools, from a list obtained from the Ministry of Education (MoE) website. The list was then verified with the MoE and the directorates of education. The student list was obtained from the selected schools and all eligible students were invited to participate with the prior permission of the school principal. Participants of the study equally represented the 3 variables: sex (male) female), school type (public/private) and residential area (eastern/western Amman). Samples were selected using 3 stages: stage 1 was selection of area and schools (private/public, male/ female): stage 2 was selection of classes (years 10, 11 and 12) and stage 3 was selection of the study participants. Classes within pre-selected schools were chosen randomly, and all students from the selected grade were surveyed. Students participated in the study voluntarily, they were informed about the survey and written consent was obtained prior their completing the questionnaire. The eastern and western parts of Amman were chosen to represent low and high socioeconomic status (SES) areas respectively.

Prior to commencing the survey, approval from the MoE in Jordan was obtained for conducting the survey. Ethical clearance for the study was obtained from the University of Sydney human research ethics committee (protocol no. 10785).

\section{Instrument}

The instrument of the study was based on the lung cancer and smoking survey developed by the American Cancer Society (11) and founded on the health belief model (10). The original questionnaire was written in English and translated into Arabic (the main language of the participants) by a certified translator. The translated instrument was verified by the first author (H.S.), 2 academics of the University of Sydney and 2 health professionals in Jordan who are bilingual (Arabic is their first language), and any differences were reconciled. The questionnaire was pilot tested on 30 students to test the readability of the translated instrument and ease and clarity in answering the survey questions. Participants of the pilot study were not involved in the final study. The survey collected data on participants' background information, their smoking behaviour, family history of smoking, knowledge of lung cancer, perceptions 
of the seriousness of lung cancer and perceptions of their own susceptibility to lung cancer. Students were asked to state their daily allowance (in Jordanian dinars, where 1 dinar = US\$ 1.4) in order to measure their ability to access cigarettes.

Participants' knowledge oflung cancer was assessed by 14 statement-type questions testing their knowledge about lung cancer symptoms (e.g. "If I had lung cancer, I would know because it causes chest pain") and detection (e.g. "The best way to find out if I have lung cancer is to have a chest X-ray") and other related questions, with response options of agree or disagree (11). Perceived susceptibility to and severity of lung cancer were assessed with statement-type questions rated on a 5-point Likert-type scale from strongly agree $=1$, to strongly disagree $=5$. Perceived susceptibility was measured with 8 questions (e.g. "If I was a smoker, the probability of acquiring lung cancer is higher"), while perceived seriousness was assessed by 5 questions (e.g. "If I develop lung cancer, I would get to a point where I could not do any daily activities") (11). Scores on each module of the statement-type questions were separately converted into a percentage score out of 100 and presented as mean and standard deviation (SD) scores, whereby a lower mean indicated lower knowledge, lower perception of susceptibility and lower perception of seriousness.

\section{Data analysis}

Bivariate analysis including the chisquared, Mann-Whitney U test, t-test and analysis of variance (ANOVA) and multivariate analysis including multiple linear regression analysis were conducted using SPSS, version 17 . The multiple linear regression analysis was performed to determine THE significant predictors of perceived susceptibility of lung cancer (outcome variable), once a significant association had been determined between predictors and criterion (outcome) variables using bivariate analyses.

\section{Results}

\section{Demographic data}

The 648 participants were equally distributed by sex, school type and location. Students from the western part of Amman (high SES) received a significantly higher daily allowance (median JD 0.97) than their peers in the east of the capital (low SES) (median JD 0.84) $(Z=-3.569,2$-sided $P \leq 0.001)$. A similar pattern was seen according to school type, whereby students in public schools received a lower daily allowance (median JD 0.78) compared with their counterparts in private schools (median $=J D$ 1.01 $)(Z=-7.333,2-$ sided $P \leq$ 0.001 ).

\section{Smoking behaviour}

The data on participants' smoking behaviour showed that $43.5 \%$ had smoked daily for 1 year at any point in time prior to or at the time of the survey (ever smokers). Of the ever smokers, 63.5\% (27.6\% of the total participants) were current smokers at the time of the survey. The majority of smokers (42.0\%) consumed 1-2 cigarettes daily, with more than half obtaining their cigarettes primarily from shops (53.9\%), followed by friends (51.4\%) and family (36\%) (multiple responses). One-quarter $(25.0 \%)$ of students reported starting smoking at age $\leq 14$ years.

The data on family smoking showed that the great majority of students (81.0\%) had a smoker in the family, primarily the father $(51.2 \%)$, followed by a brother (37\%); more than twothirds $(70.8 \%)$ of these family members smoked on a daily basis.

\section{Knowledge about lung cancer}

The means score for knowledge about lung cancer was 46.3\% (SD $12.2 \%$ ) (95\% CI: 45.4-47.3\%); range $7.1-85.7 \%$.
Knowledge of lung cancer was significantly higher (mean score $50.4 \%$ (SD 11.3\%) among those who started smoking at a younger age ( $<12$ years) compared with those started at an older age (> 16 years) (mean score $44.6 \%$ $(\mathrm{SD} 11.1 \%)(F=2.371, P<0.05)$.

Bivariate results show that students in western Amman (high SES) (89.2\%) were more knowledgeable than their peers in eastern Amman (low SES) (82.7\%) about the best way to diagnose lung cancer $\left(\chi^{2}=5.63, P<0.02\right)$, its symptoms and possible causes (Table 1). Government-school students and those who lived in eastern Amman (low SES) were more knowledgeable about the prognosis and fatality of lung cancer (e.g. in the statement "More people die of lung cancer than any other form of cancer") compared with students in private school and those who lived in western Amman (high SES) $\left(\chi^{2}=3.56\right.$, $P<0.05$ ) (Table 1).

Female students scored higher than their male counterparts on knowledge of the symptoms of lung cancer $(76.5 \%$ versus $65.4 \%)\left(\chi^{2}=11.8, P<0.01\right)$ and the possible relationship between smoking and weight loss $(65.7 \%$ versus $54.3 \%)\left(\chi^{2}=11.8, P<0.01\right)($ Table 1$)$. They were also more knowledgeable about passive smoking and the possible negative effects of smoking, i.e. lung cancer. Females also knew more of the effects of chemotherapy than males did $(70.7 \%$ versus $57.7 \%)\left(\chi^{2}=11.8, P<\right.$ 0.01) (Table 1).

Students in western Amman (higher SES) demonstrated significantly better knowledge than their counterparts in eastern Amman concerning the effects of chemotherapy ( $68.2 \%$ versus $60.2 \%)$ $\left(\chi^{2}=4.53, P<0.03\right)$ and radiotherapy (53.1\% versus $45.4 \%)\left(\chi^{2}=3.86, P<\right.$ 0.05) (Table 1).

The results also showed that knowledge of smoking-related consequences was associated with duration of smoking as well as the age of commencing smoking. 


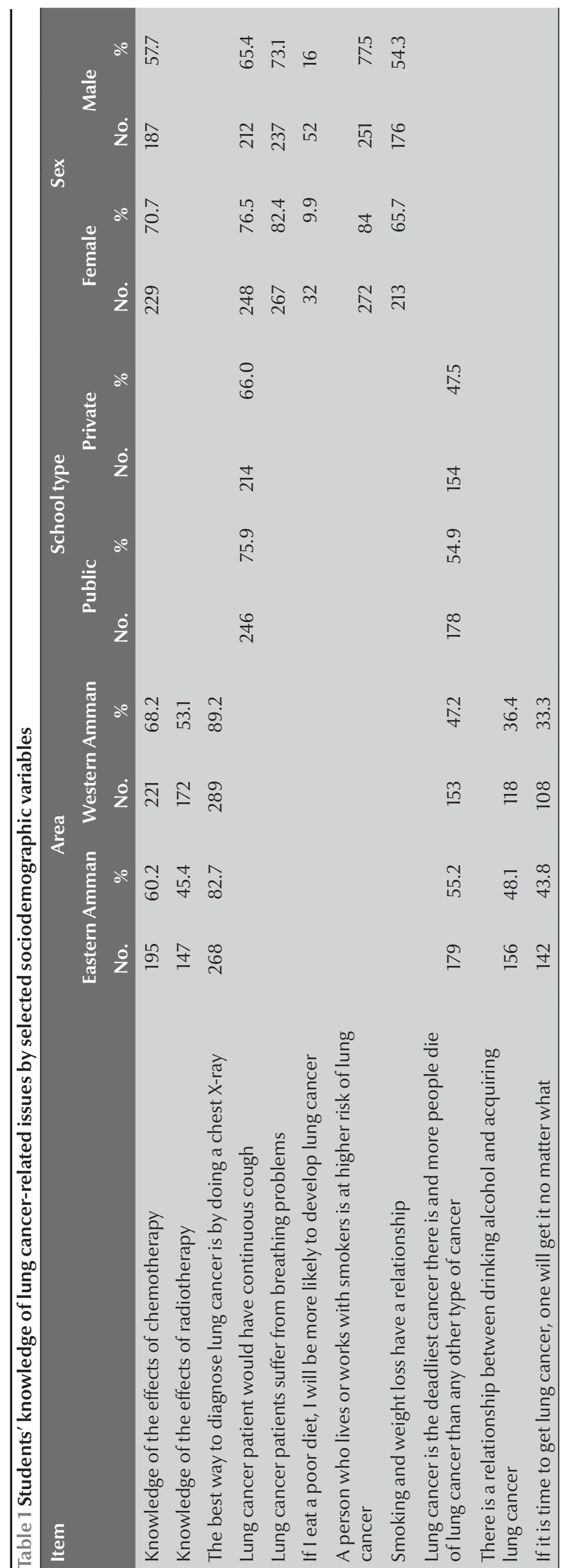

\section{Perceived susceptibility to lung cancer}

A small proportion (10.1\%) of the surveyed students believed that their susceptibility to lung cancer was high, while more than half (52.0\%) of the students saw their susceptibility as low and the remainder $(37.9 \%)$ were unsure. The mean score for perceived susceptibility to lung cancer was $62.4 \%$ (SD 12.3\%) (95\% CI: 61.5-63.4\%); range 12.5-100\%.

A far higher percentage of the students in high SES western Amman (58.3\%) perceived themselves as having low susceptibility to lung cancer compared with their counterparts living in low SES eastern Am$\operatorname{man}(45.4 \%)\left(\chi^{2}=12.1, P<0.05\right)$.

Perceived susceptibility to lung cancer was assessed against participants' smoking variables (Table 2). Results from both t-test and ANOVA show that current smokers, those who smoked rarely and those who smoked 1-2 cigarettes per day perceived themselves to be more susceptible to acquiring lung cancer than those who consumed more cigarettes per day. Also, students who depended on their family as the main supplier of cigarettes, and those who bought their cigarettes by the pack, perceived themselves to be more susceptible to lung cancer compared with students who depended on other sources including friends for cigarettes and those who purchased cigarettes singly $(P<0.05)$ (Table 2$)$.

The association between perceived susceptibility to lung cancer among other diseases and the sociodemographic variables of students is shown in Table 3. Sex and school location (residential area and SES) were significantly associated with perceived susceptibility to certain diseases. Females and students living in the eastern suburbs of Amman believed themselves to be more susceptible to the listed diseases than their male counterparts and students living in western Amman.

\section{Perceived seriousness of lung cancer}

The mean score for perceived seriousness of lung cancer was $61.8 \%$ (SD 15.6\%) (95\% CI: 60.6-63.0\%); range $20.0-100 \%$.

Students in grade 10 [mean score $65.1 \%$ (SD $14.7 \%)$ ] perceived lung cancer to be more serious than did students in grades 11 [mean score $60.2 \%$ (SD 15.4\%)] and final year 12 [mean score 60.1\% $(\mathrm{SD} 16.1 \%)](F=7.455, P<0.001)$. In addition, students in eastern Amman (lower SES) [mean score $63.1 \%$ (SD 15.1\%)] perceived lung cancer to be more serious than did students in Western Amman 


\begin{tabular}{|c|c|c|c|c|c|}
\hline \multirow[t]{2}{*}{ Smoking variable } & \multirow[t]{2}{*}{ No. } & \multicolumn{2}{|c|}{$\begin{array}{l}\text { Perceived susceptibility to } \\
\text { lung cancer }\end{array}$} & \multirow[t]{2}{*}{ Test statistic } & \multirow[t]{2}{*}{$P$-value } \\
\hline & & Mean score & (SD) & & \\
\hline \multicolumn{6}{|c|}{ Ever smoked daily for 1 year? } \\
\hline Yes & 282 & 61.8 & (12.4) & $t=1.205$ & \\
\hline No & 366 & 62.9 & (12.1) & & 0.228 \\
\hline \multicolumn{6}{|c|}{ Status of current smoking } \\
\hline Yes & 179 & 62.9 & (12.1) & $F=4.850$ & \\
\hline No & 103 & 60.2 & $(12.7)$ & & 0.008 \\
\hline Never & 366 & 64.5 & (11.5) & & \\
\hline \multicolumn{6}{|l|}{ How often do you smoke? } \\
\hline Daily & 85 & 59.2 & (12.5) & $F=3.193$ & \\
\hline Sometimes & 72 & 61.0 & (13.1) & & 0.023 \\
\hline Rarely & 125 & 63.8 & (11.7) & & \\
\hline Never & 366 & 62.9 & (12.1) & & \\
\hline \multicolumn{6}{|c|}{ No. of cigarettes smoked daily } \\
\hline 0 & 366 & 62.9 & $(12.1)$ & $F=3.235$ & \\
\hline $1-2$ & 118 & 64.3 & $(12.2)$ & & 0.012 \\
\hline $3-5$ & 56 & 59.4 & $(12.2)$ & & \\
\hline $6-10$ & 48 & 62.0 & (11.7) & & \\
\hline$>10$ & 60 & 58.6 & $(13.0)$ & & \\
\hline \multicolumn{6}{|c|}{ Age when you start smoking (years) } \\
\hline$<12$ & 52 & 61.3 & $(12.2)$ & $F=0.465$ & \\
\hline $12-14$ & 111 & 62.3 & $(13.0)$ & & 0.76 \\
\hline $14-16$ & 99 & 61.6 & (12.8) & & \\
\hline$>16$ & 20 & 60.8 & $(7.8)$ & & \\
\hline Non-smoker & 366 & 62.9 & $(12.1)$ & & \\
\hline \multicolumn{6}{|c|}{ Type of tobacco (smokers only) } \\
\hline Cigarettes & 191 & 60.7 & $(12.4)$ & $F=0.482$ & \\
\hline Cigars & 104 & 60.8 & (11.7) & & 0.749 \\
\hline Pipe & 35 & 61.8 & $(10.2)$ & & \\
\hline Self-rolled cigarettes & 38 & 62.8 & (11.4) & & \\
\hline Waterpipe & 212 & 62.1 & $(12.5)$ & & \\
\hline \multicolumn{6}{|c|}{ Source of tobacco (smokers) } \\
\hline Shop & 152 & 60.0 & $(12.0)$ & & \\
\hline Friends & 145 & 61.8 & $(12.5)$ & $F=2.520$ & \\
\hline Family & 103 & 64.5 & (13.5) & & 0.041 \\
\hline Street & 29 & 60.3 & (12.5) & & \\
\hline Other & 32 & 59.6 & $(10.0)$ & & \\
\hline \multicolumn{6}{|c|}{ How do you buy tobacco? } \\
\hline By pack & 214 & 62.6 & (11.7) & $F=2.982$ & \\
\hline By singles & 68 & 59.0 & (14.4) & & 0.050 \\
\hline Never & 366 & 62.9 & (12.1) & & \\
\hline
\end{tabular}

$S D=$ standard deviation . 


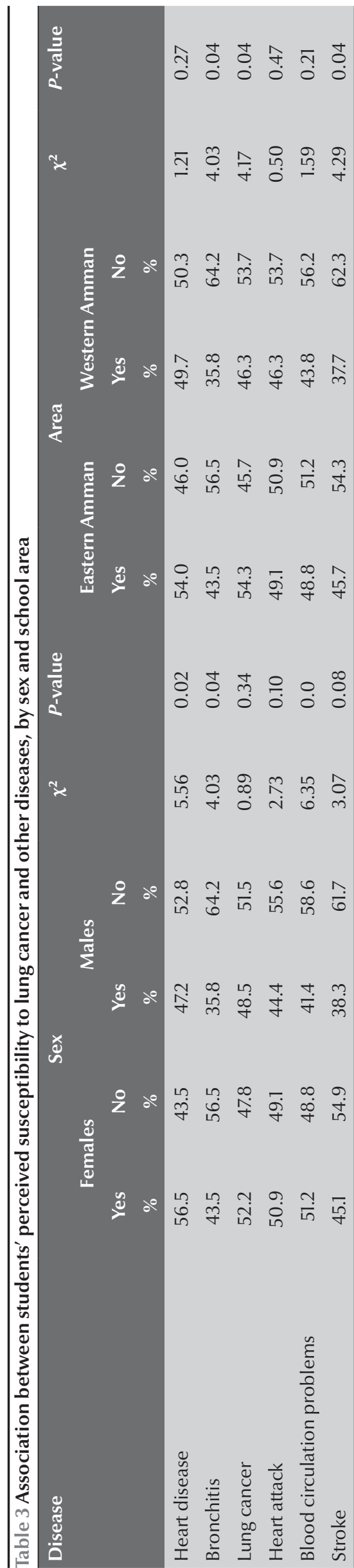

(higher SES) [mean score 60.5\% $(\mathrm{SD} 15.9 \%)](t=2.175, P<0.05)$.

\section{Multivariate analyses}

Multiple linear regression analyses were carried out to predict perceived susceptibility to lung cancer (criterion/outcome variable) in relation to demographic and other smoking-related variables and perceived seriousness of the disease (as predictor variables). To determine which of the sociodemographic variables could significantly predict the outcome variable, regression analysis using dummy variables was carried out. The results showed that female students perceived themselves to be more susceptible to lung cancer than their male counterparts $(P$ $<0.001$ ), and students who perceived lung cancer to be more serious also perceived themselves to be more susceptible to the disease compared with their counterparts $(P<0.005)$ (Table 4). The model explained $11.7 \%$ of the variance in the perceived susceptibility to lung cancer (criterion/outcome variable).

\section{Discussion}

This survey showed a high prevalence of current smoking among the studied students at $27.6 \%$. We can locate very few studies that target this exact age group of Jordanian youth in order to compare our findings. This scarcity of studies was also reported by Alzyoud et al., who concluded that the prevalence of smoking waterpipes increased with age; for example, more of the 15-16 years old schoolstudents smoked (40\%) than their 17-18-year-old counterparts (19\%) (12). Compared with our findings the GYTS in 2001 and 2007 conducted crosssectional surveys on a younger age group (13-15 year olds) and reported lower prevalences of current smoking of $10.8 \%$ and $19.8 \%$ respectively $(9,13)$. A recent study of 7 th grade students (a younger cohort) in Irbid, Jordan also reported a lower prevalence of current smoking (7) compared with our study. Of 3 different studies performed on university students in Jordan, one revealed a similar prevalence rate of smoking to our sample (14), the second showed a lower prevalence (15), while the most recent study documented a much higher prevalence (16).

Studies performed on comparable age groups in neighbouring countries within the Eastern Mediterranean Region (EMR) reported lower prevalence rates of current smokers: $14.1 \%$ in the United Arab Emirates (17) and 10.8\% in Riyadh, Saudi Arabia (18). In Egypt, the GYTS revealed that $4 \%$ of $13-15$ year olds were current smokers in 2005 (13), a considerably lower figure than the $19.8 \%$ reported in Jordan by the same study. In the latest GYTS survey, Jordan ranked 4th from among 15 countries, (after Palestine West Bank, Syrian Arab Republic and Kuwait), with regard to the prevalence of current smoking (13).

The number of cigarettes smoked is an important indicator of both addiction to and accessibility of tobacco products. Our results showed that the majority of smokers (42.0\%) smoked 1-2 cigarettes daily, while less than a quarter smoked more than 10 cigarettes per day. As a comparison, approximately $80 \%$ of students surveyed in Malaysia smoked less than 3 cigarettes per day (19). These differences in consumption may be explained by differences in SES, students' ability to purchase tobacco products and peer pressure.

Despite laws that prohibit the sale of tobacco products to children under 18 years in Jordan, $65.0 \%$ of the current smokers surveyed found it easy to buy cigarettes in a shop or on the street. By comparison, only $40.6 \%$ students in Riyadh region and 38\% of 


\begin{tabular}{|c|c|c|c|c|c|c|}
\hline \multirow[t]{2}{*}{ Independent variable } & \multicolumn{2}{|c|}{$\begin{array}{l}\text { Unstandardized } \\
\text { coefficient }\end{array}$} & \multirow[t]{2}{*}{$\begin{array}{c}\text { Beta } \\
\text { coefficient }\end{array}$} & \multirow[t]{2}{*}{$t$-value } & \multirow[t]{2}{*}{$P$-value } & \multirow[t]{2}{*}{$95 \% \mathrm{Cl}$ for beta } \\
\hline & $B$ & SE & & & & \\
\hline Age & 0.89 & 0.87 & 0.06 & 1.01 & 0.31 & $(-0.84$ to 2.61$)$ \\
\hline Sex (male) & 6.52 & 1.54 & 0.26 & 4.22 & $<0.001$ & (3.48 to 9.56$)$ \\
\hline School location (eastern Amman) & 1.23 & 1.52 & 0.05 & 0.81 & 0.419 & $(-1.76$ to 4.22$)$ \\
\hline School type (public) & -1.05 & 1.50 & -0.04 & 0.70 & 0.484 & $(-4.01$ to 1.90$)$ \\
\hline Knowledge about lung cancer. & -0.11 & 0.06 & -0.11 & 1.71 & 0.088 & $(-0.23$ to 0.02$)$ \\
\hline Perceived severity of lung cancer & 0.13 & 0.05 & 0.17 & 2.82 & 0.005 & (0.04 to 0.22$)$ \\
\hline Constant & 40.00 & 16.76 & - & - & - & - \\
\hline$R^{2}$ value (\%) & 11.7 & - & - & - & - & - \\
\hline
\end{tabular}

$S E=$ standard error $; C l=$ confidence interval.

Malaysian students managed to buy their cigarettes from shops $(18,19)$ and depended instead on social sources.

The well-documented strong correlation between adolescent smoking and family smoking habits (20) was confirmed by our study results; it was also confirmed in a qualitative study by the authors on the same age group of students (21).

Our study suggest that students smoke not because of lack of knowledge about the risks of smoking but due to some misguided beliefs and attitudes, such as the connection between smoking and weight loss, to reduce anxiety and boredom and to enhance attention and concentration, and due to factors such as the family environment and school location. Similar factors were identified by a recent study in Irbid, Jordan (7). With regard to sex differences, female students had a better understanding of the symptoms of lung cancer and possible negative effects of smoking concerning lung cancer. This finding of our study concurs with the findings of Prescott et al. in Denmark (22).

The findings of the multiple regression analysis showed that the age of starting smoking was the only factor to predict knowledge of lung cancer. This could be because those who started smoking at a younger age have been smoking for longer and have had more time to think about it and consider it a real threat. A study of adolescents in the United States (mean age 14 years) coincides with this findings, suggesting that adolescents' perceived less risk of adverse effects from smoking so-called "light" cigarettes (23). However, no study on teenagers' age at initiation to smoking and their knowledge of possible impact of smoking (i.e. lung cancer) in Jordan was available to compare our results with.

Our finding that females felt more susceptible to heart disease, bronchitis and blood circulation diseases than did males is well-supported by studies elsewhere, some of which were on different age groups (22). This, in addition to cultural reasons, might explain why smoking is less prevalent among female students than males in this part of the world. Interestingly, students in eastern Amman (low SES) felt more susceptible to bronchitis, lung cancer and stroke than their peers in western Amman (high SES). This result contradicts the majority of the published literature as it has been hypothesized that those from lower SES are more susceptible to becoming smokers because they usually have lower education and hence feel less vulnerable to acquiring dangerous diseases (24). An explanation for our finding could be that those from western Amman have the financial means to purchase cigarettes and thus continue smoking. Our findings also concur with a WHO report showing that poor or deprived categories of society smoke more than other groups, in all regions of the world except in the EMR, where high income seems to be a factor in smoking (1).

It is important to acknowledge that the data reported in this study pertain to cigarette smoking only and do not include other types of smoking, such as waterpipes, a habit that is on the rise among young people, especially females, within the EMR. The results of this study cannot be generalized to all Jordanian youth of the same age category. The survey was restricted to 16-18-year-old students attending certain schools in the eastern and western suburbs of the capital of Jordan only and does not necessarily reflect the smoking behaviour of other Jordanian students.

\section{Conclusions}

The high prevalence of current smoking (27.6\%) and past smoking (43.6\%) among 16-18-year-old school students in Jordan in conjunction with their high exposure to passive smoking in the home environment $(70.8 \%$ reported daily smokers in the family) is alarming. Despite the existence of legislation to prevent it, students' access to tobacco 
products from shops, friends and family members appears to be uninhibited.

Knowledge of lung cancer was higher among those who started smoking before the age of 12 years, i.e. those who have been smoking for longer. Only one-tenth of the surveyed students believed themselves to be highly susceptible to the disease; more than half rated their susceptibility as low. Females and students living in low SES areas felt more susceptible to the disease than those from a higher SES background. Feeling more susceptible to lung cancer appeared to increase the seriousness with which the disease was perceived.

As a signing party to the $\mathrm{WHO}$ Framework Convention on Tobacco Control, Jordan is committed to certain legislation, regulations and laws to enforce tobacco control among different components of society especially youth. However, it appears that smoking is prevalent among Jordanian youth and that the dangers of smoking, in particular the threat of lung cancer, are not taken very seriously. It also appears that attempts to curtail youth smoking have not been overly effective thus far.

The authors suggest that this study covers a gap in the literature about this particular age group (16-18 years), a very important segment of the population of Jordan. Our findings should provide valuable information to policymakers seeking to tackle the problem of youth smoking not only in Jordan but elsewhere in the EMR. The findings of our study will contribute to a better understanding of those young people's smoking behaviour and the way they perceive cigarette smoking and its possible consequences. The findings of gender and SES differences in the perceived seriousness of and susceptibility to lung cancer point to areas that could be specifically targeted to increase awareness of the consequences of smoking.
Further research should be conducted in other regions and other sectors of Jordanian society in order to strengthen our understanding of young people's smoking behaviour and their perception of certain risk behaviours in order to help policy-makers enact effective policies to curb these dangerous behaviours.

\section{Acknowledgements}

We would like to thank the Ministry of Education of Jordan and all participating schools administrations as well as the participating students for their contribution to the success of this study.

Funding: The authors declare that the project was not financially supported or sponsored by any organization and no financial relationship with the schools involved in the project.

Competing interests: None declared.

\section{References}

1. Systematic review of the link between tobacco and poverty. Geneva: World Health Organization; 2011 (http://whqlibdoc. who.int/publications/2011/9789241500548_eng.pdf, accessed 15 December 2014).

2. Jha P, Chaloupka FJ. Tobacco control in developing countries. Oxford: Oxford University Press; 2000.

3. Countries: Jordan. World Bank [Internet] (http://www.worldbank.org/en/country/jordan, accessed 15 December 2014).

4. Jordan human development report. The youth of Jordan. New York (NY): United Nations Development Program; 2004 (http://hdr.undp.org/en/reports/nationalreports/arabstates/jordan/name,3277,en.html, accessed 15 December 2014).

5. Burgan SZ. Smoking behavior and views of Jordanian dentists: A pilot survey. Oral Surg Oral Med Oral Pathol Oral Radiol Endod. 2003 Feb;95(2):163-8. PMID:12582355

6. Warren CW, Lea V, Lee J, Jones NR, Asma S, McKenna M Change in tobacco use among 13-15 year olds between 1999 and 2008: findings from the Global Youth Tobacco Survey. Glob Health Promot. 2009 Sep;16(2) Suppl:38-90. PMID:19770234

7. McKelvey K. Wilcox, ML, Madhivanan P, Mzayek F, Khader Y, Wasim, et al. Time trends of cigarette and waterpipe among a cohort of school children in Irbid, Jordan, 2008-11. Eur J Public Health. 2013;23:862-7. PMID:24078649

8. Department of Statistics. The Hashemite Kingdom of Jordan [Internet] (http://www.dos.gov.jo/dos_home_e/main/index. $\mathrm{htm}$, accessed 15 December 2014).

9. Meyasser Z. Jordan national behavioral risk and chronic disease survey/Jordan 2004/2005 (http://www.who.int/chp/
steps/JordanSTEPSPresentation.pdf, accessed 15 December 2014).

10. Stretcher $\mathrm{V}$, Rosenstock IM. The health belief model. In: Glanz $\mathrm{K}$, Lewis FM, Rimer BK, editors. Health behavior and health education: theory, research and practice. 2nd ed. San Francisco (CA): Jossey-Bass; 1997.

11. Price JH, Everett SA. Perceptions of lung cancer and smoking in an economically disadvantaged population. J Community Health. 1994 Oct; 19(5):361-75. PMID:7836557

12. Alzyoud S, Weglicki LS, Kheirallah KA, Haddad L, Alhawamdeh KA. Waterpipe smoking among middle and high school Jordanian students: patterns and predictors. Int J Environ Res Public Health. 2013 Dec;10(12):7068-82. PMID:24351734

13. El-Awa F, Warren CW, Jones NR. Changes in tobacco use among 13-15-year-olds between 1999 and 2007: findings from the Eastern Mediterranean Region. East Mediterr Health J. 2010 Mar;16(3):266-73. PMID:20795439

14. Haddad LG, Malak MZ. Smoking habits and attitudes towards smoking among university students in Jordan. Int J Nurs Stud. 2002 Nov;39(8):793-802. PMID:12379297

15. Kofahi MM, Haddad LG. Perceptions of lung cancer and smoking among college students in Jordan. J Transcult Nurs. 2005 Jul;16(3):245-54. PMID:15980052

16. Khader YS, Alsadi AA. Smoking habits among university students in Jordan: prevalence and associated factors. East Mediterr Health J. 2008 Jul-Aug;14(4):897-904. PMID:19166173

17. Bener A, al-Ketbi LM. Cigarette smoking habits among high school boys in a developing country. J R Soc Promot Health. 1999 Sep;119(3):166-9. PMID:10518355 
18. Al-Bedah AM, Qureshi NA. The Global Youth Tobacco Survey: 2001-2002 in Riyadh region, the Kingdom of Saudi Arabia. Subst Abuse Rehabil. 2011;2:197-204. PMID:24474857

19. Lim KH, Sumarni MG, Kee CC, et al. Prevalence, smoking habit and factors related to smoking and nicotine among lower secondary school male students in Kota Tinggi District, Johor, Malaysia. Malaysian Journal of Public Health Medicine. 2010;10(1):28-37.

20. Darling N, Cumsille P. Theory, measurement, and methods in the study of family influences on adolescent smoking. Addiction. 2003 May;98 Suppl 1:21-36. PMID:12752360

21. Shadid HM, Hossain SZ. Understanding smoking behavior among secondary school students in Amman, Jordan: a qualitative study. J Community Med Health Educ. 2013;3:2.
22. Prescott E, Bjerg AM, Andersen PK, Lange P, Vestbo J. Gender difference in smoking effects on lung function and risk of hospitalization for COPD: results from a Danish longitudinal population study. Eur Respir J. 1997 Apr;10(4):822-7. PMID:9150319

23. Kropp RY, Halpern-Felsher BL.. Adolescents' beliefs about the risks involved in smoking "light" cigarettes. Pediatrics. 2004 Oct;114(4):e445-51. PMID:15466070

24. Finkelstein DM, Kubzansky LD, Goodman E. Social status, stress, and adolescent smoking. J Adolesc Health. 2006 Nov;39(5):678-85. PMID:17046504 